\title{
Thermodynamic Analysis of Precipitation Process of MX-type Phases in High Strength Low Alloy Steels
}

\author{
Marek Opiela ${ }^{1}$ \\ 1 Faculty of Mechanical Engineering, Silesian University of Technology, ul. Konarskiego 18A, 44-100 Gliwice, \\ Poland \\ E-mail: marek.opiela@polsl.pl
}

\begin{abstract}
The paper presents the results of thermodynamic analysis of precipitation process of MX-type interstitial phases in austenite. The subject of the investigation were two newly developed high strength low alloy microalloyed steels with similar concentration of $\mathrm{C}$ and $\mathrm{N}$ and with diversified amount of $\mathrm{Nb}$, Ti and $\mathrm{V}$ microadditions. Thermodynamic analysis of the state of phase equilibrium of structural constituents, taking into consideration the austenite of investigated microalloyed steels, was mainly focused on analytic calculations of chemical composition of austenite and the content and chemical composition of potential MX-type interstitial phases (M - metal, X-metalloid) as a function of heating or cooling temperature. The analysis of precipitation process of complex carbonitrides in austenite under thermodynamic equilibrium conditions has allowed to define stoichiometric compositions of carbonitrides as a function of temperature along with determination of their volume portion. This study was based on the model proposed by Hillert and Staffanson, which was subsequently developed by Adrian. The results of performed investigation can be used to develop the appropriate parameters of thermomechanical treatment of metallurgical products from the tested HSLA-type steels.
\end{abstract}

Keywords: HSLA-type steels, MX-type phases, precipitation, carbonitrides

\section{INTRODUCTION}

Precipitates of interstitial phases, i.e. carbides, nitrides and the products of their mutual solubility - carbonitrides, play an important role in shaping mechanical properties of HSLA (High Strength Low Alloy) type microalloyed steels. A stability of these phases depends mainly on their chemical composition, while the temperature of their dissolution can vary over a wide range. In the technological process of steel products manufacturing, it allows to obtain a variety of structural effects, such as: controlling austenite grain size at high temperature through undissolved particles of precipitates, changing the kinetics of recrystallization and phase transitions induced by dissolved elements and precipitates, achieving the strengthening effect through fine-dispersive precipitates of carbonitrides formed at low temperature $[8,11,23,29]$.
A study of strengthening mechanisms indicates that the most important are: strengthening from grain boundaries, solution hardening, strain hardening and precipitation strengthening $[7,35,36]$. In case of microalloyed steels, precipitation strengthening and strengthening from grain boundaries have the most significant influence on mechanical properties, yet it is difficult to unequivocally separate the effects deriving from individual strengthening mechanisms [6, $31,33]$. Therefore, controlling the strengthening mechanisms requires a multi-scale analysis and computer-aided modelling. The effectiveness of individual strengthening mechanisms is determined by chemical composition of steel and the parameters of plastic working. High strength and plastic properties of steels with ferritic-pearlitic microstructure are achieved by grain refinement and precipitation strengthening. Whereas, mechanical properties of toughened steels depend on the strengthening coming from grain refinement 
of austenite induced with precipitation of interstitial phases, precipitation strengthening and from martensitic type phase transitions. Therefore, the knowledge of chemical constitution of austenite and the content of precipitates, controlling grain growth of this phase and influencing precipitation strengthening effect, has a very essential practical meaning. It makes possible to optimize the chemical composition of steel allowing, at the lowest possible production costs, to attain appropriate microstructure, which determines acquiring desired mechanical properties.

The production of metallurgical products with desired functional properties from HSLA type steel requires optimal selection of hot working parameters, taking into consideration the process of precipitation of carbides, nitrides and carbonitrides of microadditions introduced into the steel in austenite $[17,30,39]$. Proper understanding of the impact of these phases on the processes taking place during hot working and during cooling of products from the end temperature of this treatment, requires knowledge of the formation mechanism of these phases and their stability in austenite. Thermodynamic models of precipitation of simple carbides and nitrides have been presented in the works of Lin and Melloy [21, 27], while thermodynamic models concerning formation of complex carbonitrides were analyzed by Adrian et al. [1-3, $18,22,25,38,40]$. Solubility of carbide or nitride in austenite is determined by the logarithm of the solubility product expressed as [13]:

$$
\log ([M] \cdot[X])=B-A / T
$$

where: $[M]$ and $[X]$ - mass fraction (in weight \%) of metallic microaddition and metalloid dissolved in austenite at temperature $\mathrm{T}$ (in $\mathrm{K}$ ), respectively, $A$ and $B$ - constants connected to free enthalpy of MX phase formation.

Chemical composition of austenite, as well as the portion of undissolved $<\mathrm{MX}>$ compound can be determined using solubility product of the compound and the mass balance of the elements included in the reaction, wherein the product is the $<\mathrm{MX}>$ compound. A simplified thermodynamic model based on the laws of thermodynamic equilibrium, concerning precipitation of $<\mathrm{MX}>$ compound, is described by the system of equations $[1,2]$ :

$$
\begin{gathered}
{[M] \cdot[X]=k_{M X}} \\
M=[M]+\left[\frac{(M)}{(M X)}\right]\langle M C\rangle
\end{gathered}
$$

$$
X=[X]+\left[\frac{(M)}{(M X)}\right]\langle M X\rangle
$$

where: $\mathrm{k}_{\mathrm{MX}}$ - product of the solubility compound MX, M and X - total contents of these elements in steel in $\mathrm{wt} \%,<\mathrm{MX}>-$ content of undissolved compound MX in wt $\%$ while the atomic and molar weight of the elements and compounds is presented as symbols put in ( ) parentheses.

The HSLA microalloyed steels are widely used for highly loaded welded constructions, selfpropelled lifting and port devices, oil and gas pipelines, drilling platforms, bridges, means of heavy transport, and recently, more and more often, for high-quality forgings [28, 34, 44-46]. Meeting the increasing demands of forgings customers, especially the requirements of the automotive industry, connected with the increase in strength and maintaining required ductility and fracture toughness, is believed to be possible through full use of microadditions. In case of HSLA-type steels, the increase in strength is related to grain refinement and precipitation hardening by dispersive particles of carbides, nitrides and carbonitrides $[9,10,41,42]$. The analysis of publications related to manufacturing of forgings with the use of thermomechanical treatment reveals that the studies conducted so far have been focused on introducing $\mathrm{V}[15,24,32,37]$ and $\mathrm{Ti}$ and $\mathrm{V}[4,5$, $7,39]$ microadditions into steel. Very few studies on combined application of $\mathrm{Nb}$, Ti and $\mathrm{V}$ creates the necessity to perform more detailed analysis of understanding of the complex interaction of MXtype interstitial phases containing $\mathrm{Nb}$, $\mathrm{Ti}$ and $\mathrm{V}$ and the process of their precipitation.

The aim of the study is to analyze the precipitation process of MX-type interstitial phases in austenite in newly developed microalloyed HSLA-type steels.

\section{MATERIALS AND METHODS}

The subject of the research were newly elaborated microalloyed HSLA-type steels with chemical composition presented in Table 1 . Chemical composition of examined steels was developed on the basis of detailed analysis of the literature $[4,5,7,15,24,32,37,39]$ in terms of the production of forgings using thermomechanical treatment method. 
Table 1. Chemical composition of investigation steels [4, 5, 7, 15, 24, 32, 37, 39]

\begin{tabular}{|c|c|c|c|c|c|c|c|c|c|}
\hline \multirow{2}{*}{ Steel } & \multicolumn{10}{|c|}{ Mass contents, wt \% } \\
\cline { 2 - 21 } & $\mathrm{C}$ & $\mathrm{Mn}$ & $\mathrm{Si}$ & $\mathrm{Mo}$ & $\mathrm{Cr}$ & $\mathrm{Nb}$ & $\mathrm{Ti}$ & $\mathrm{V}$ & $\mathrm{N}$ \\
\hline $\mathrm{A}$ & 0.31 & 1.45 & 0.30 & 0.22 & 0.26 & - & 0.033 & 0.008 & 0.0043 \\
\hline $\mathrm{B}$ & 0.28 & 1.41 & 0.29 & 0.22 & 0.26 & 0.027 & 0.028 & 0.019 & 0.0039 \\
\hline
\end{tabular}

The melts, made in the VSG-100S type laboratory vacuum induction furnace, are characterized with low fraction of phosphorus and sulphur, i.e. $0.006 \% \mathrm{P}$ and $0.004 \% \mathrm{~S}$ in steel $\mathrm{A}$ and 0.008 $\% \mathrm{P}$ and $0.004 \% \mathrm{~S}$ in steel B. Melted steels have similar concentration of C, Mn, Si, Mo, Cr and N. However, significant differences concern the content of metallic microadditions introduced into the steel. The purpose of introducing Ti and V microadditions into steel $\mathrm{A}$, and in case of steel $\mathrm{B}$ also a microaddition of $\mathrm{Nb}$, was to acquire MX-type interstitial phases (carbides, nitrides and carbonitrides). Precipitation of these phases in austenite gives the opportunity to produce fine-grained microstructure of steel products, which is decisive for obtaining high strength properties and high crack toughness, also at reduced temperature.

Preliminary tests performed on a laboratory scale showed satisfactory results concerning mechanical properties. Steel A, hardened directly from forging finish temperature equal $900^{\circ} \mathrm{C}$, subsequently subjected to tempering at the temperature of $650^{\circ} \mathrm{C}$, presents the following mechanical properties: $\mathrm{YS}_{0.2} \sim 880 \mathrm{MPa}$, UTS $\sim 939 \mathrm{MPa}, \mathrm{UEl}$ $\sim 13 \%$ and $\mathrm{KV}^{-40} \sim 69 \mathrm{~J}$. While steel B - obtained under similar conditions shows: $\mathrm{YS}_{0.2} \sim 920 \mathrm{MPa}$, UTS $\sim 974 \mathrm{MPa}, \mathrm{UEl} \sim 15 \%$ and $\mathrm{KV}^{-40} \sim 83 \mathrm{~J}$.

A thermodynamic analysis of the state of phase equilibrium of the structural constituents, taking into account the austenite of the investigated microalloyed steels, was mainly focused on analytic calculations of the chemical composition of austenite and the content and chemical composition of the potential MX-type interstitial phases of microalloying elements as a function of the heating or cooling temperature. The analysis of the precipitation process of carbides and nitrides in austenite, under conditions of thermodynamic equilibrium, was carried out using the simplified model proposed by Adrian [2] (equations (2) $\div(4)$ ) and modified with an assumption, that carbides and nitrides precipitate simultaneously. The modified model is described by the following system of equations:

$$
\begin{aligned}
& {[M] \cdot[C]=k_{M C}} \\
& {[M] \cdot[N]=k_{M N}}
\end{aligned}
$$

$$
\begin{gathered}
M=[M]+\frac{(M)}{(M C)}\langle M C\rangle+\frac{(M)}{(M N)}\langle M N\rangle \\
C=[C]+\frac{(C)}{(M C)}\langle M C\rangle \\
N=[N]+\frac{(N)}{(M N)}\langle M N\rangle
\end{gathered}
$$

The solution of the system of equations has the form:

$$
\begin{gathered}
{[M]^{2}+[M]\left\{\frac{(M)}{(C)} C+\frac{(M)}{(N)} N-M\right\}-} \\
-\frac{(M)}{(C)} k_{M C}-\frac{(M)}{(N)} k_{M N}=0
\end{gathered}
$$

Calculations of the simultaneous precipitation of carbide, $\mathrm{MC}$, and nitride, $\mathrm{MN}$, was carried out for the steel A only. This steel contains $0.033 \% \mathrm{Ti}$ and a low content of V $(0.008 \%)$, which can be omitted because of low content and lower chemical affinity to interstitials compared to Ti. This element may form VC carbide in ferrite during cooling from the austenite temperature range.

The analysis of precipitation of complex carbonitrides under conditions of thermodynamic equilibrium, was performed with the use of the thermodynamic model of Adrian [1] based on Hillert and Staffansson model [16]. The CarbNit computer program was used to evaluate the precipitation process of complex carbonitrides [19]. The program allows to calculate the chemical composition of austenite of the examined microalloyed steels and, in particular, to define the relationships between contents of elements dissolved in austenite, $[\mathrm{M}]$, $[\mathrm{X}]$ and temperature, $[\mathrm{M}]=\mathrm{f}(\mathrm{T})$ and $[\mathrm{X}]=\mathrm{f}$ (T). It also allows to determine the chemical constitution of complex phases of carbonitrides and to define their volume fraction as a function of temperature, $V_{V}=f(T)$ based on the implemented thermodynamic model. For steel B, containing simultaneous additions of three microalloying elements $(0.028 \% \mathrm{Ti}, 0.027 \% \mathrm{Nb}$ and $0.019 \% \mathrm{~V}$ ) calculations was performed using the thermodynamic model for carbonitrides precipitates. Physical data for thermodynamic 
Table 2. A summary of physical data and solubility temperatures of individual interstitial phases

\begin{tabular}{|c|c|c|c|c|c|c|}
\hline \multirow{2}{*}{ No } & \multirow{2}{*}{$\begin{array}{c}\text { Type of } \\
\text { MX phase }\end{array}$} & \multirow{2}{*}{$\begin{array}{c}\text { Density } \\
\mathrm{g} / \mathrm{cm}^{3}\end{array}$} & \multicolumn{2}{|c|}{ Solubility product constants } & \multicolumn{2}{|c|}{ Solubility temperature, ${ }^{\circ} \mathrm{C}$} \\
\cline { 4 - 7 } & & $\mathrm{A}$ & $\mathrm{B}$ & steel A & steel B \\
\hline 1. & $\mathrm{TiN}$ & 5.43 & 15490 & 5.19 & 1440.9 & 1419.6 \\
\hline 2. & $\mathrm{TiC}$ & 4.94 & 10745 & 5.33 & 1194.9 & 1172.1 \\
\hline 3. & $\mathrm{NbC}$ & 7.79 & 7900 & 3.42 & - & 1152.6 \\
\hline 4. & $\mathrm{NbN}$ & 7.30 & 10800 & 3.70 & - & 1133.7 \\
\hline 5. & $\mathrm{VC}$ & 5.65 & 9500 & 6.72 & 745.7 & 783.2 \\
\hline 6. & $\mathrm{VN}$ & 6.10 & 7840 & 3.02 & 801.9 & 848.1 \\
\hline
\end{tabular}

Table 3. Atomic masses of elements

\begin{tabular}{|c|c|c|c|c|}
\hline $\mathrm{Ti}$ & $\mathrm{Nb}$ & $\mathrm{V}$ & $\mathrm{C}$ & $\mathrm{N}$ \\
\hline 47.9 & 92.9 & 50.94 & 12.01 & 14.008 \\
\hline
\end{tabular}

calculation (solubility products constants, A, $\mathrm{B}$ and densities of binary compounds, $\rho_{\mathrm{MX}}$ ) are given in Table 2. In this table solubility temperatures in austenite for considered binary compounds assuming only one interstitial element, ( $\mathrm{C}$ or $\mathrm{N}$ is present) are presented. Atomic masses of Ti, Nb, V, C, N are presented in Table 3.

Chemical composition of MX-type interstitial phases, revealed in the examined steels, was assessed using the TITAN80-300 transmission electron microscope equipped with the EDS energy dispersion spectrometer.

In order to verify the applied model, studies were carried out on the influence of the temperature, increasing programmatically, on mean diameter of austenite grains. Specimens with a diameter of $10 \mathrm{~mm}$ were austenitized in a temperature range from $900^{\circ} \mathrm{C}$ to $1200^{\circ} \mathrm{C}$, with gradation of $50^{\circ} \mathrm{C}$ for 15 minutes, and then quenched in water. Prepared metallographic specimens were etched in an aqueous solution of picric acid at the temperature of $50^{\circ} \mathrm{C}$. The average grain diameter was determined on the basis of the standard [48] using Leica Qwin software, cooperating with Leica MEF 4A light microscope.

\section{RESULTS}

The analysis of the presence of MX-type single interstitial phases in solid solution does not reflect the real situation satisfactorily, as all of the discussed phases exhibit mutual solubility in a solid state and typically precipitate as complex carbonitrides [3]. As a consequence, both the start and finish temperature of their precipitation undergo a change.
Comparison of analysis results of chemical constitution of austenite and concentration of undissolved Ti compounds, using the simplified model of independent precipitation of TiN nitride and $\mathrm{TiC}$ carbide and the model of precipitation of $\mathrm{TiC}_{\mathrm{y}} \mathrm{N}_{1-\mathrm{y}}$ carbonitride, is presented in Fig. 1. Analysis results of the content of double compounds formed in steel $\mathrm{A}$, TiN and $\mathrm{TiC}$, which precipitate independently as a function of temperature, are shown in Fig. 1a. In a temperature range of $1441 \div 1150^{\circ} \mathrm{C}$, only TiN nitride can precipitate. Its volume fraction, $\mathrm{V}_{\mathrm{v}}$, increases with a temperature decrease to approximately $0.027 \%$. At the temperature of $\mathrm{TiC}$ carbide precipitation start and almost does not change with further decrease of temperature. As shown in Fig. 1b, at the temperature of $1150^{\circ} \mathrm{C}$ almost all nitrogen is bound into TiN. Remaining dissolved Ti (approximately $0.019 \%$ ) reacts with $\mathrm{C}$ forming $\mathrm{TiC}$ carbide upon further decrease of temperature. The volume fraction $\mathrm{V}_{\mathrm{v}}$ of this compound increases to about $0.037 \%$ at $800^{\circ} \mathrm{C}$. At this temperature, microaddition of Ti is practically bound in precipitates (Fig. $1 \mathrm{c})$, and the content of carbon in the solution remains at the level of $0.0305 \%$ (Fig. 1d).

In case of the further temperature decrease, dissolved carbon may react with $\mathrm{Fe}$ and other microadditions (e.g. V) present in steel, especially in the temperature range of austenite transformation into ferrite or pearlite, since solubility of interstitial elements (and microadditions) in ferrite is much lower than in austenite.

Precipitates formed in ferrite are much smaller in size, compared to precipitates formed in austenite, and cause the effect of precipitation strengthening. Comparing temperature-dependent total volume fraction of $\mathrm{TiC}$ carbide and $\mathrm{TiN}$ 
a)

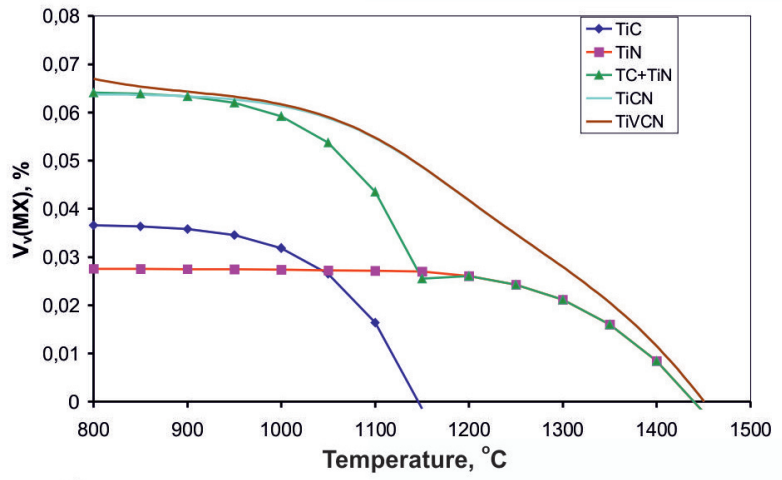

c)

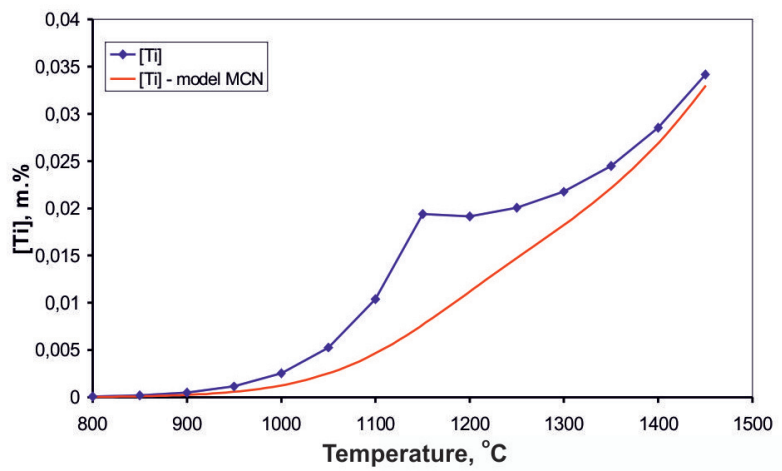

b)

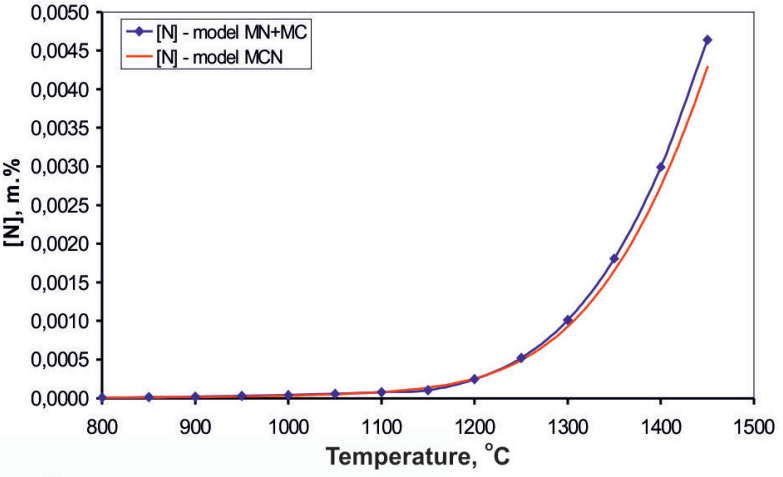

d)

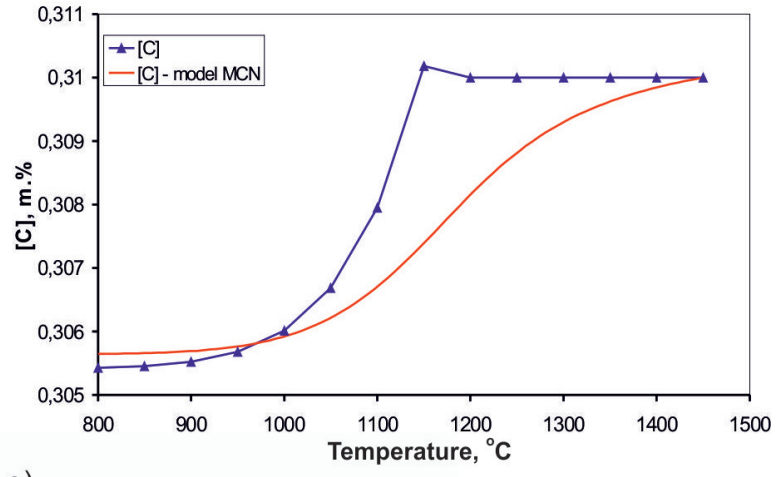

e)

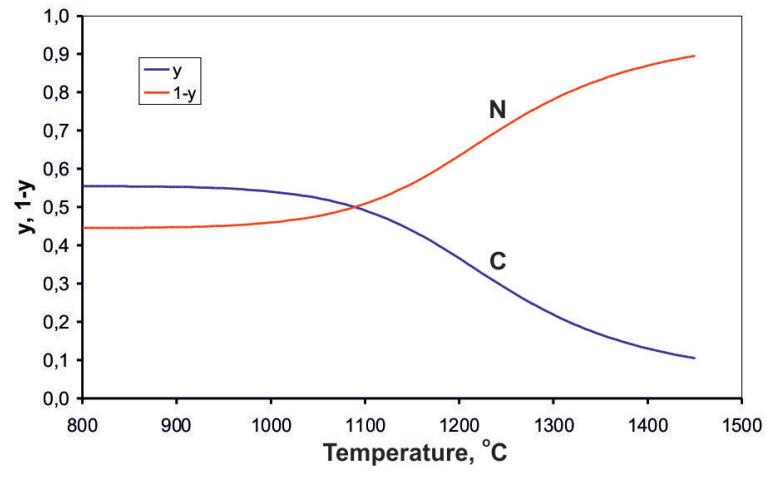

Figure 1. The results of thermodynamic analysis of the Ti compounds precipitates in steel A; relationships of: a) $\left.\mathrm{V}_{\mathrm{v}}=\mathrm{f}(\mathrm{T}), \mathrm{b}\right)[\mathrm{N}]=\mathrm{f}(\mathrm{T})$, c) $\left.[\mathrm{Ti}]=\mathrm{f}(\mathrm{T}), \mathrm{d}\right)[\mathrm{C}]=\mathrm{f}(\mathrm{T})$,

e) atomic fraction $\mathrm{C}$ and $\mathrm{N}$ in $\mathrm{TiC}_{\mathrm{y}} \mathrm{N}_{1-\mathrm{y}}$ carbonitride, as a function of temperature nitride as well as $\mathrm{Ti}(\mathrm{C}, \mathrm{N})$ carbonitride in Fig. 1a, it can be observed that formation of carbonitride, as an effect of mutual dissolution of compounds of double precipitates, results in the increase in their content, when compared to the state of independent precipitation of TiN and TiC. Hence, lower concentration of elements dissolved in austenite, [Ti], [N] and [C], calculated according to the model of carbonitride precipitation, in comparison with the simplified model for independent precipitation of double compounds. The dependence of chemical constitution of $\mathrm{TiC}_{\mathrm{y}} \mathrm{N}_{1-\mathrm{y}}$ carbonitride on temperature is shown in Fig. 1e. As it can be noted, the content of nitrogen in carbonitride increases along with the increase in austenitizing temperature, while concentration of carbon decreases.

The results of thermodynamic analysis of carbonitride precipitation in steel $\mathrm{B}$ are presented in Fig. 2. The effect of austenitizing temperature on chemical composition of formed $\mathrm{Ti}_{x} \mathrm{Nb}_{\mathrm{v}} \mathrm{V}_{1-\mathrm{x}-\mathrm{v}} \mathrm{C}_{\mathrm{y}} \mathrm{N}_{1 \text { - }}$ y carbonitride is presented in Fig. $2 \mathrm{a}$. It can be observed, that the content of $\mathrm{Ti}$ and $\mathrm{N}$ increases in the carbonitride with the increase of temperature, while concentration of carbon and other metallic elements decreases. Along with increase of temperature, $(\mathrm{Ti}, \mathrm{Nb}, \mathrm{V})(\mathrm{C}, \mathrm{N})$ carbonitride transits successively into $(\mathrm{Ti}, \mathrm{Nb})(\mathrm{C}, \mathrm{N})$ and $\mathrm{TiN}$. Calculated 
a)

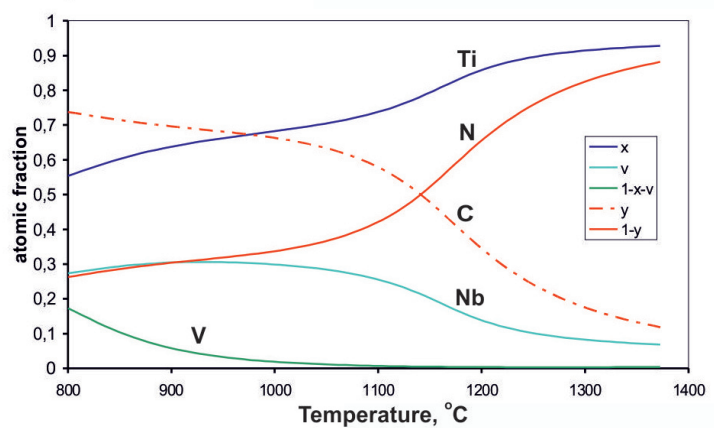

c)

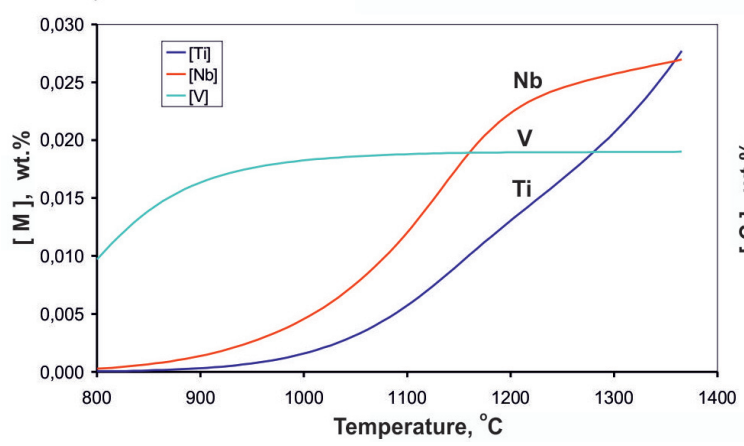

b)

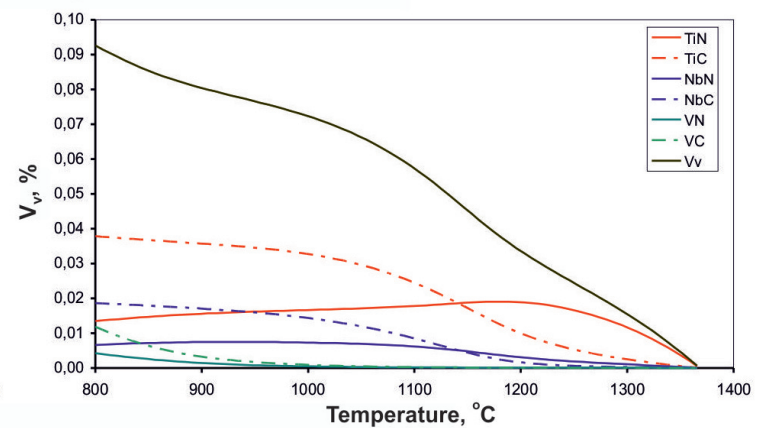

d)

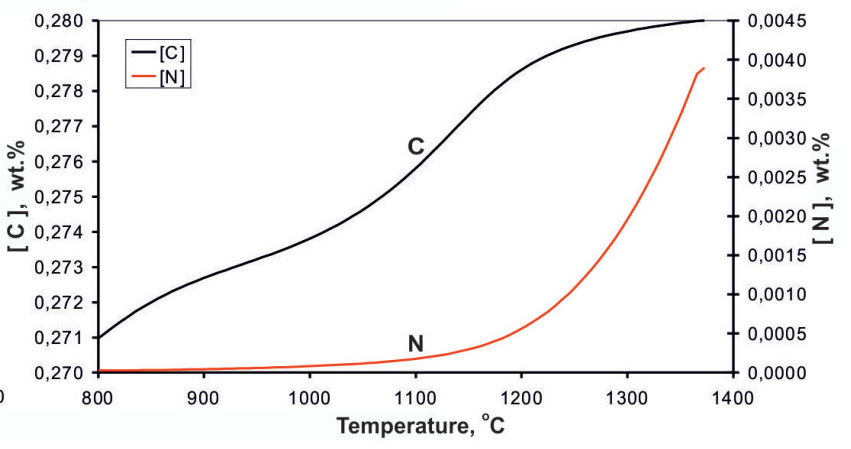

Figure 2. The results of thermodynamic analysis of $\mathrm{Ti}_{\mathrm{x}} \mathrm{Nb}_{\mathrm{v}} \mathrm{V}_{1-\mathrm{x}-\mathrm{v}} \mathrm{C}_{\mathrm{y}} \mathrm{N}_{1-\mathrm{y}}$ carbonitride precipitation in steel B; dependence of: a) carbonitride chemical constitution, b) carbonitride concentration, c) metallic elements dissolved in austenite, d) interstitial elements dissolved in austenite, as a function of temperature

stoichiometric composition of the complex carbonitride at the temperature of $850^{\circ} \mathrm{C}$ is equal $\mathrm{Ti}$ ${ }_{0.600} \mathrm{Nb}_{0.293} \mathrm{~V}_{0.107} \mathrm{C}_{0.745} \mathrm{~N}_{0.255}$ and changes into carbonitride $\mathrm{Ti}_{0.794} \mathrm{Nb}_{0.202} \mathrm{~V}_{0.004} \mathrm{C}_{0.478} \mathrm{~N}_{0.522}$ at $1150^{\circ} \mathrm{C}$. Microaddition of $\mathrm{V}$ is completely dissolved in austenite at the temperature of $1200^{\circ} \mathrm{C}$ with the following calculated stoichiometric composition of the carbonitride: $\mathrm{Ti}_{0.858} \mathrm{Nb}_{0.142} \mathrm{C}_{0.344} \mathrm{~N}_{0.656}$. Dissolution temperature of $\mathrm{Ti}_{0.928} \mathrm{Nb}_{0.072} \mathrm{C}_{0.122} \mathrm{~N}_{0.878}$ complex carbonitride is equal $1366^{\circ} \mathrm{C}$. The effect of temperature on volume fraction of the carbonitride is shown in Fig. 2b. The diagram also presents a change in volume fractions of double compounds, $\mathrm{TiC}, \mathrm{NbC}$ and $\mathrm{VC}$ carbides and TiN, $\mathrm{NbN}$, and $\mathrm{VN}$ nitrides, dissolved in carbonitride, depending on temperature. At temperatures above $1150^{\circ} \mathrm{C}$, TiN nitride predominates in the carbonitride, while at the temperature of $800^{\circ} \mathrm{C}$ the concentration of $\mathrm{TiC}$ prevails.

The influence of austenitizing temperature on chemical composition of austenite is presented in Figures 2c, d. Along with the temperature decrease, concentration of $\mathrm{Ti}, \mathrm{Nb}$ and $\mathrm{V}$ metallic elements and $\mathrm{C}$ and $\mathrm{N}$ interstitial elements dissolved in austenite decreases. The rate of these changes depends on the type of the element. Concentration of $\mathrm{Ti}$ and $\mathrm{Nb}$ as well as $\mathrm{N}$ decreases faster, while in case of $\mathrm{V}$ and $\mathrm{C}$ - the slowest.
Changes in concentration of carbon do not exceed $0.01 \%$ in a considered temperature range. It can be observed that at $900^{\circ} \mathrm{C}$, concentration of $\mathrm{Ti}$ and $\mathrm{N}$ dissolved elements practically decreases to 0 . There are mainly $\mathrm{V}$ and $\mathrm{C}$ remaining in the solution. During further cooling, these elements form a fine-grained VC carbide, which causes the effect of precipitation strengthening.

The process of precipitation of interstitial phases in a matrix was examined in transmission electron microscope on water-hardened samples. The effects of precipitation in the austenite, inherited in martensite, were analyzed by means of electron diffraction, X-ray microanalysis and verified during dark-field observations. These techniques were used complementarily to the analysis of matrix microstructure as well as to the identification and determination of morphology of observed precipitates of nitrides, carbides and carbonitrides of $\mathrm{Ti}, \mathrm{Nb}$ and $\mathrm{V}$ microadditions.

Investigation of microstructure of thin foils taken from the water-hardened steel A, revealed in the microstructure of lath martensite matrix precipitates, mainly TiN nitrides, $\mathrm{TiC}$ carbides and $\mathrm{Ti}(\mathrm{C}, \mathrm{N})$ carbonitrides, undissolved during austenitizing, located mainly inside martensite laths (Fig. 3). The presence of these phases in the matrix was found primarily using energy dispersion 

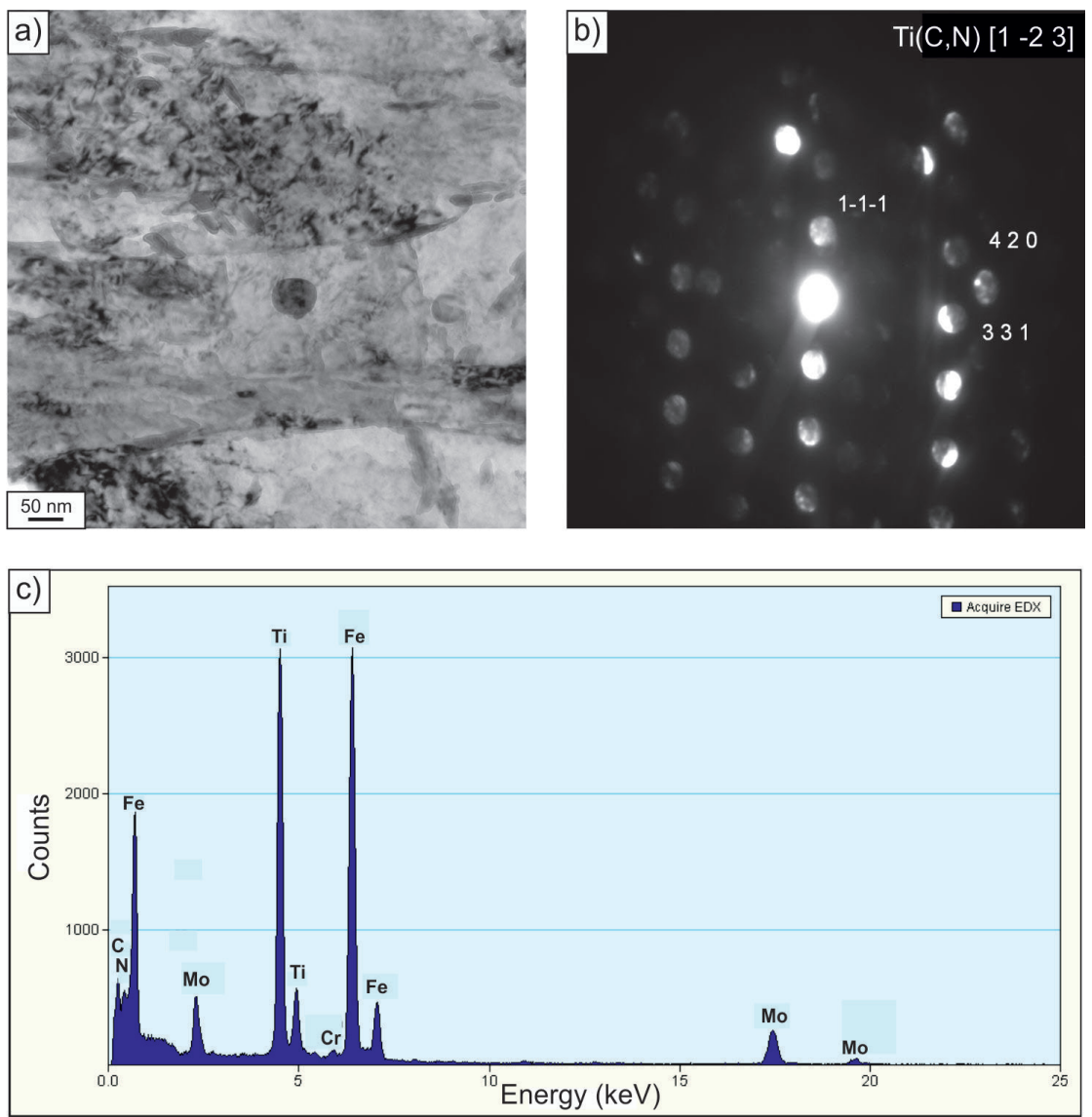

Figure 3. Titanium carbonitride $\mathrm{Ti}(\mathrm{C}, \mathrm{N})$ in the martensite of steel A (a), microdiffraction of the precipitate (b), EDS spectrum (c); austenitizing temperature of $900^{\circ} \mathrm{C}$

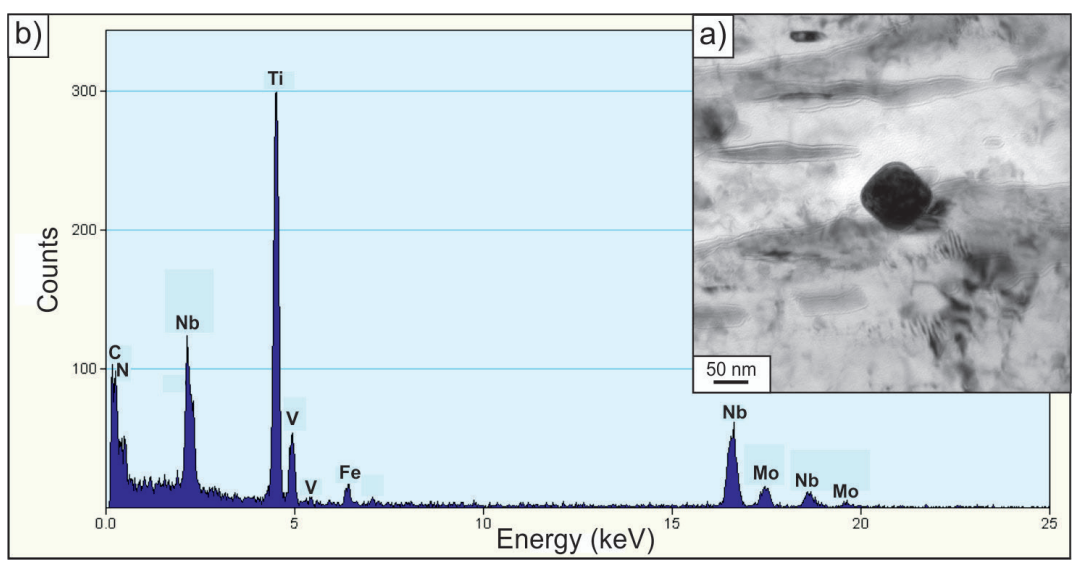

Figure 4. Carbonitride $(\mathrm{Ti}, \mathrm{Nb}, \mathrm{V})(\mathrm{C}, \mathrm{N})$ in the martensite of steel B (a), EDS spectrum (b); austenitizing temperature of $900^{\circ} \mathrm{C}$

spectroscopy and micro-diffraction methods from micro-region of precipitates.

However, in the microstructure of hardened steel $\mathrm{B}$, containing $\mathrm{Ti}, \mathrm{Nb}$ and $\mathrm{V}$ microadditions, mainly $(\mathrm{Ti}, \mathrm{Nb}, \mathrm{V})(\mathrm{C}, \mathrm{N})$ complex carbonitrides were revealed - Figure 4. In microstructure of specimens austenitized at higher temperature, the presence of TiN nitrides and $(\mathrm{Ti}, \mathrm{Nb})(\mathrm{C}, \mathrm{N})$ type carbonitrides was also found. The microstructure observations in transmission electron microscope fully correspond with the analysis results of interstitial phases precipitation in investigated microalloyed HSLA-type steels.

Testing results of the influence of austenitizing temperature on grain size of primary austenite are presented in Figure 5. As shown in the data presented in this figure, examined steels retain finegrained microstructure in the lower austenitizing 


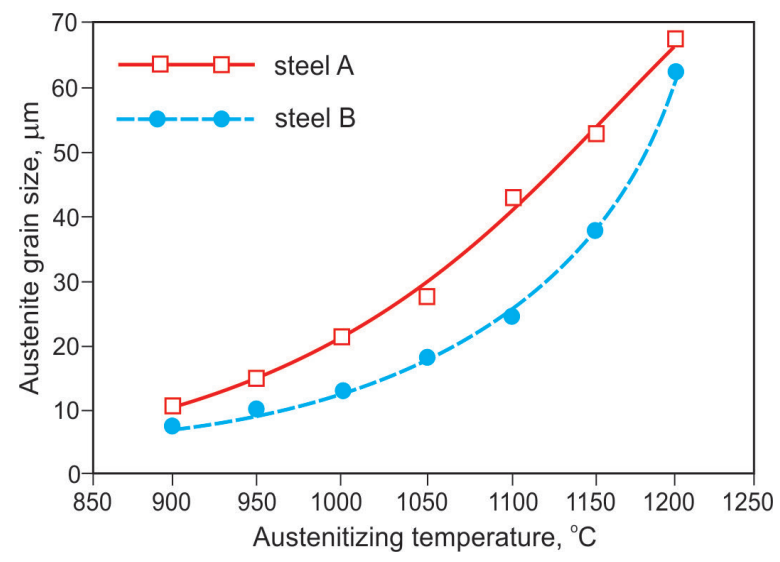

Figure 5. Influence of the austenitizing temperature on the austenite grain size

temperature range. Steel A, after austenitizing at the temperature of $900^{\circ} \mathrm{C}$, reveals an average austenite grain diameter of approx. $12 \mu \mathrm{m}$, and after austenitizing at the temperature of $1050^{\circ} \mathrm{C}$ - approx. $26 \mu \mathrm{m}$. In the same temperature range, the mean diameter of primary austenite grains of steel B varies from $8 \mu \mathrm{m}$ to $17 \mu \mathrm{m}$. More distinct growth of austenite grains was observed after exceeding the temperature of $1050^{\circ} \mathrm{C}$, more intense in case of steel A.

\section{DISCUSSION}

The analysis conducted here allowed to determine the type and temperature range of the precipitation of interstitial phases in steel $\mathrm{A}$ and B. Taking into account the temperature factor of solubility products of the analyzed phases which can potentially be formed in the investigated microalloyed steels, it can be stated that TiN-, TiCand $\mathrm{VC}, \mathrm{VN}$-type phases precipitate in steel $\mathrm{A}$, and in steel $\mathrm{B}$ also $\mathrm{NbC}$ and $\mathrm{NbN}$. The analysis of the presence of single MX-type interstitial phases (Table 2) in solid solution does not satisfactorily present the actual situation, as all of the individual phases reveal partially mutual solubility, and therefore an additional analysis of the precipitation of complex carbonitrides which can potentially precipitate in the examined steels under conditions of thermodynamic equilibrium was carried out. The analysis was carried out using the thermodynamic model developed by Adrian [1] based on Hillert and Staffansson [16]. In steel containing microadditions of $\mathrm{Ti}$ and $\mathrm{V}$, a complex $(\mathrm{Ti}, \mathrm{V})(\mathrm{C}, \mathrm{N})$-type carbonitride can be formed under conditions of thermodynamic equilibrium, and in steel additionally containing the microaddition of $\mathrm{Nb}-(\mathrm{Ti}, \mathrm{Nb}, \mathrm{V})(\mathrm{C}, \mathrm{N})$-type complex carbonitride. It is necessary to emphasize that a cooling rate may affect a type of compound precipitated in austenite with decreasing temperature. With the higher cooling rate precipitation of binary compounds, carbides and nitrides, is preferred and a simplified model for independent carbides, MC, and nitrides, $\mathrm{MN}$, precipitation may be a useful tool to predict chemical composition of austenite and undissolved compound contents. But at lower cooling rates or holding material at constant austenitizing temperature, the model of carbonitrides precipitation is more suitable.

Similar issues, concerning the process of precipitation of MX-type interstitial phases in high strength low alloy steels, as well as those related to modelling and kinetics of this process, were analyzed in the works $[1-3,10,12,14,18,43$, $46,47]$. Chen et al. [10] investigated the hardening process of HSLA steel containing $0.1 \% \mathrm{C}$, $1.5 \% \mathrm{Mn}, 0.2 \% \mathrm{Mo}, 0.2 \% \mathrm{Ti}$ and $0.04 \% \mathrm{Nb}$ by complex (Ti, Mo)C and (Ti, Nb)C type carbides. Thermodynamic analysis of the precipitation process of niobium carbonitrides in austenite, ferrite and at the boundaries of these phases was carried out in [18]. The work consisted in examination of the thermodynamics and kinetics of niobium carbonitrides precipitations, as well as the influence of plastic deformation and the temperature on the kinetics of precipitations with the aim to determine the amount of niobium in a solid solution.

Evaluated course of changes in the size of austenite grains as a function of austenitizing temperature is typical for HSLA-type steels, austenitized under similar conditions [20, 26]. Conducted studies of the impact of austenitizing temperature on the grain size of primary austenite revealed that steels retain fine-grained microstructure in a temperature range from $900^{\circ} \mathrm{C}$ to $1050^{\circ} \mathrm{C}$. The reason for maintaining fine-grained microstructure of austenite in this temperature range is the presence of a significant portion of undissolved TiN, Ti $(\mathrm{C}, \mathrm{N})$ particles in steel $\mathrm{A}$ and $\mathrm{B}$ and partially undissolved $(\mathrm{Ti}, \mathrm{V})(\mathrm{C}, \mathrm{N})$ particles in steel $\mathrm{A}$, and also $(\mathrm{Ti}, \mathrm{Nb}, \mathrm{V})(\mathrm{C}, \mathrm{N})$ in steel $\mathrm{B}$. The presence of these phases in the microstructure contributes to the effective inhibition of austenite grain growth. Increase of austenitizing temperature causes grain growth of austenite, yet the growth is significantly lower in steel containing $\mathrm{Nb}$ microaddition. The course of the curve in Fig. 5, obtained for steel with microaddition of 
$\mathrm{Nb}$, is more characteristic for microalloyed steels, and the growth of austenite grains in the steel should be connected with dissolution of complex carbides and carbonitrides (Fig. 2). Austenitizing specimens at the temperature of $1200^{\circ} \mathrm{C}$ results in formation of microstructure with an average diameter of austenite grains equal $68 \mu \mathrm{m}$ and 62 $\mu \mathrm{m}-$ for steel A and B, respectively. At this temperature, the fraction of particles in both steels is comparable and consists only of phases rich in $\mathrm{Ti}$, which leads to obtaining similar grain size. It should be pointed out that acquired values of the mean diameter of the $g$ phase grains, after austenitizing at the temperature of $1200^{\circ} \mathrm{C}$, are several times lower when comparing to conventional C-Mn steels, where the average diameter of austenite is within the range of 150 to $300 \mu \mathrm{m}$ [13, 20]. The research carried out on the influence of the austenitizing temperature on the grain size of the g phase correlates well with analysis results of the MX-type interstitial phase precipitation process, according to the model proposed by Adrian.

Dong L. et al. [12] have obtained comparable results of the impact of austenitizing temperature on the austenite grain size of steel with chemical composition similar to the examined steels. In the work, the evolution of the size of carbonitrides and their influence on the size of primary austenite grains in ultra-high strength microalloyed steel were studied. It was revealed that the average size of austenite grains slowly increased along with the temperature increase in the lower austenitizing temperature range. Rapid growth of austenite grains - very similar to the results presented in the paper - was observed after exceeding the temperature of approx. $1050^{\circ} \mathrm{C}$. Moreover, it was demonstrated that fine $\mathrm{Nb}$-rich precipitations have the greatest effect on the delay of the austenite grain growth process.

\section{CONCLUSIONS}

The paper presents an thermodynamic analysis of the precipitation of MX-type phases in high strength low alloy steels under equilibrium conditions. Performed research allowed to formulate the following conclusions:

1. The analysis of the presence of MX-type single interstitial phases in solid solution does not reflect the real situation satisfactorily, as all of the discussed phases exhibit mutual solubility in a solid state and typically precipitate as complex carbonitrides. As a consequence, both the start and finish temperature of their precipitation undergo a change,

2. In steel containing microadditions of Ti and $\mathrm{V}$ (steel A), a complex (Ti,V)(C,N)-type carbonitride can be formed under conditions of thermodynamic equilibrium, and in steel additionally containing the microaddition of $\mathrm{Nb}$ (steel $\mathrm{B}$ ) $(\mathrm{Ti}, \mathrm{Nb}, \mathrm{V})(\mathrm{C}, \mathrm{N})$-type complex carbonitride,

3. Examined steels retain fine-grained microstructure of austenite after austenitizing in a temperature range from $900^{\circ} \mathrm{C}$ to $1050^{\circ} \mathrm{C}$. The average diameter of austenite grains increases in the mentioned temperature range from $12 \mu \mathrm{m}$ to $26 \mu \mathrm{m}$ for steel A and from $8 \mu \mathrm{m}$ to $17 \mu \mathrm{m}$ for steel B,

4 . The result of maintaining fine-grained microstructure of austenite in this temperature range is the presence of a significant portion of undissolved TiN, Ti $(\mathrm{C}, \mathrm{N})$ particles in steel A and B and partially undissolved $(\mathrm{Ti}, \mathrm{V})(\mathrm{C}, \mathrm{N})$ particles in steel $\mathrm{A}$, and also $(\mathrm{Ti}, \mathrm{Nb}, \mathrm{V})(\mathrm{C}, \mathrm{N})$ in steel $\mathrm{B}$,

5. Determined average diameter of austenite grains in examined steels is comparable to the mean diameter of the phase in Ti-V and Ti-Nb-V steels, after austenitizing under the same conditions.

The results of performed investigation can be used to develop the appropriate parameters of thermomechanical treatment of metallurgical products from the tested HSLA-type steels.

\section{Acknowledgements}

The author is grateful to Prof. Henryk Adrian of the Faculty of Metals Engineering and Industrial Computer Science, AGH University of Science and Technology in Krakow, for his scientific discussions and help in thermodynamic calculations.

\section{REFERENCES}

1. Adrian H.: Thermodynamic model for precipitation of carbonitrides in high strength low alloyed steels up to three microalloying elements with or without additions of aluminium. Materials Science and Technology 8, 1992, 406-420.

2. Adrian H.:Thermodynamic calculations of carbonitride precipitation as a guide for alloy design of microalloyed steels. Proceedings of the International Conference "Microalloying'95", Pittsburgh, USA 1995, 285-305.

3. Adrian H., Głowacz E., Augustyn-Pieniążek J., Matusiewicz P., Marynowski P.: Kinetics of carbo- 
nitrides precipitation in microalloyed steels. Proceedings of the Conference „Polish Metalurgy in 2011-2014 years“, Polish Metallurgy Commitee, Kraków, Poland, 2014, 837-854.

4. Babakhani A., Ziaei S.M.R., Kiani-Rashid A.R.: Investigation on the effects of hot forging parameters on the austenite grain size of vanadium microalloyed forging steel (30MSV6). Journal of Alloys and Compounds 490, 2010, 572-575.

5. Bakkali F., Chanaoui A., Dkiouak R., Elbakkali L., Al Omar A.: Characterization of deformation stability of medium carbon microalloyed steel during hot forging using phenomenological and continuum criteria. Journal of Materials Processing Technology 199, 2008, 140-149.

6. Błoniarz R., Majta J., Trujillo C., Cerreta E., Muszka K.: The mechanism for strengthening under dynamic loading for low carbon and microalloyed steel. International Journal of Impact Engineering 114, 2018, 53-62.

7. Caminaga C., Botta Filho W.J., Silva M.L.N.: Strengthening mechanism of 27MnSiVS6 microalloyed steel deformed by four different forging processes. Procedia Engineering 10, 2011, 512-517.

8. Chen C.Y., Chen S., Chen Ch., Yang J.: Control of precipitation morphology in the novel HSLA steel. Materials Science and Engineering A 634, 2015, 123-133.

9. Chen C.Y., Liao M.H.: Synergistic effects of carbon content and Ti/Mo ratio on precipitation behavior of HSLA steel: insights from experiment and critical patent analysis. Materials \& Design 186, 2020, 108361.

10. Chen C.Y., Yen H.W., Kao F.H., Li W.C., Huang C.Y., Wang S.H.: Precipitation hardening of high-strength low-alloy steels by nanometr-sized carbides. Materials Science and Engineering A 499, 2009, 162-166.

11. Clark S., Janik V., Rikenberg A.: Analysis of the extent of interphase precipitation in V-HSLA steels through in-situ characterization of the g/a transformation. Materials Characterization 115, 2016, 83-89.

12. Dong L., Liu C., Liu Y., Li C., Guo Q., Li H.: Effect of two different types of MX carbonitrides on austenite growth behavior of $\mathrm{Nb}-\mathrm{V}$-Ti microalloyed ultra-high strength steel. Fusion Engineering and Design 125, 2017, 415-422.

13. Gladman T. The Physical Metallurgy of Microalloyed Steels. The University Press, Cambridge, 1997.

14. Gui L, Long M., Zhang H., Chen D., Liu S., Wang Q., Duan H.: Study on the precipitation and coarsening of TiN inclusions in Ti-microalloyed steel by a modified coupling model. Journal of Materials Research and Technology 9(3), 2020, 5499-5514.

15. Gündüz S., Cochrane R.C.: Clustering effect on high temperature tensile behavior of vanadium microalloyed steel. Journal of Materials Processing Technology 186, 2007, 246-252.
16. Hillert M., Staffansson L.I.: The regular solution model for stoichiometric phases and ionic melts. Acta Chemica Scandinavica 24, 1970, 3618-3636.

17. Ji D., Chenxi L., Yongchang L., Chong L., Qianging G., Huijun L.: Effects of two different types of MX carbonitrides on austenite growth behavior of $\mathrm{Nb}-\mathrm{V}$ Ti microalloyed ultra-high strength steel. Fusion Engineering and Design 125, 2017, 415-422.

18. Klinkerberg K., Hulka K., Bleck W.: Niobium carbide precipitation in microalloyed steel. Steel Research 75, 2004, 744-752.

19. Krawczyk J., Adrian H.: The kinetic of austenite grain growth in steel for wind power plant shafts. Archives of Metallurgy and Materials 55, 2010, 91-99.

20. Kuziak R., Bołd T., Chen Y.: Microstructure control of ferrite-peralite high strength low alloy steels utilizing microalloying additions. Journal of Materials Processing Technology 53, 1995, 255-262.

21. Lin H.R., Hendrikson A.A.: The prediction of precipitation strengthenning in microalloyed steels. Metallurgical Transactions 19, 1988, 1471-1480.

22. Liu W.J., Jonas J.J.: Calculation of the $\operatorname{Ti}\left(\mathrm{C}_{\mathrm{y}} \mathrm{N}_{1-}\right.$ y) $-\mathrm{Ti}_{4} \mathrm{C}_{2} \mathrm{~S}_{2}-\mathrm{MnS}$ austenite equilibrium in Ti-bearing steels. Metallurgical Transactions 20, 1989, 1361-1374.

23. Liu Z.: Thermodynamic calculations of carbonitrides in microalloyed steels. Scripta Materialia 50(5), 2004, 601-606.

24. Lourenço N.J., Jorge A.M., Rollo J.M.A., Balancin O.: Plastic behavior of medium carbon vanadium microalloyed steel at temperatures near g'a transformation. Materials Research, 3, 2001, 149-156.

25. Marynowski P., Adrian H., Głowacki M., Woźny K., Koclęga D.: Modeling of the kinetics of carbonitrides precipitation proces in microalloyed steels. Proceedings of the $27^{\text {th }}$ International Conference on Metallurgy and Materials "Metal”, Brno, Czech Republic, 2018, 783-788.

26. Matlock D.K., Krauss G., Sperr J.G.: Microstructure and properties of direct-cooled microalloy forging steels. Journal of Materials Processing Technology 117, 2001, 324-328.

27. Melloy G.F., Slimmon P.R., Podgursky P.P.: Optymising the boron effect. Metallurgical Transactions 4, 1973, 2279-2289.

28. Oliveria A.P., Gonzales B.M.: The engineering behind the mechanical properties enhancement on HSLA steels, microalloyed with niobium: effect of boron and titanium. Journal of Materials Research and Technology 9(4), 2020, 9372-9379.

29. Opiela M.: Thermomechanical treatment of Ti$\mathrm{Nb}-\mathrm{V}-\mathrm{B}$ micro-alloyed steel forgings. Materiali in Tehnologije 48(4), 2014, 587-591.

30. Opiela M., Grajcar A.: Elaboration of forging conditions on the basis of the precipitation analysis of MX- 
type phases in microalloyed steels. Archives of Civil and Mechanical Engineering 12(4), 2012, 427-435.

31. Opiela M., Grajcar A.: Microstructure and anisotrophy of plastic properties of thermomechanicallyprocessed HSLA-type steel. Metals 8(5), 2018, 1-15.

32. Padmanabhan K.A., Sankaran S.: Fatigue behavior of a multiphase medium carbon V-bearing microalloyed steel processed through two thermomechanical routes. Journal of Materials Processing Technology 207, 2008, 293-300.

33. Pandit A., Murugaiyan A., Saha A., Haldar A., Bhattacharjee D., Chandra S. Ray R.K.: Strain induced precipitation of complex carbonitrides in $\mathrm{Nb}-\mathrm{V}$ and Ti-V microalloyed steels. Scripta Materialia 53(11), 2005, 1309-1314.

34. Ramachandran D., Moon J., Lee Ch., Kim S., Chung J., Biro E., Park Y.: Role of bainite microstructures with M-A constituent on the toughness of an HSLA steel for seismic resistant structural application. Materials Science and Engineering A 801(13), 2021, 140390.

35. Sanz L., Pereda B., López B.: Effect of thermomechanical treatment and coiling temperature on the strengthening mechanisms of low carbon steels microalloyed with $\mathrm{Nb}$. Materials Science and Engineering A 685(8), 2017, 377-390.

36. Skubisz P., Lisiecki Ł., Micek P.: Effect of direct cooling conditions on characteristic of drop forged $\mathrm{Ti}+\mathrm{V}+\mathrm{B}$ microalloy steel. Procedia Manufacturing 2, 2015, 428-433.

37. Skubisz P., Sińczak J., Skowronek T., Rumiński M.: Selection of direct cooling conditions for automotive lever made of microalloyed steel. Archives of Civil and Mechanical Engineering 12, 2012, 418-426.

38. Speer J.G., Michael J.R., Hansen S.S.: Carbonitride precipitation in niobium/vanadium microalloyed steels. Metallurgical and Materials Transaction A 18, 1987, 211-222.

39. Spena P.R., Firrao D.: Thermomechanical warm forging of Ti-V, Ti-Nb and Ti-B microalloyed medium carbon steels. Materials Science and Engineering A 560, 2013, 208-215.

40. Strid J., Easterling K.E.: On the chemistry and stability of complex carbides and nitrides in microalloyed steels. Acta Materialia 35, 1985, 2057-2074.

41. Wang J., Hodgson P.D., Bikmukhametor I., Miller M.K., Timokhina I.: Effects of hot-deformation on grain boundary precipitation and segregation in Ti-Mo microalloyed steels. Materials Design 141, 2018, 48-56.

42. Wang Z., Sun Y., Zhou Y., Yang Z., Jiang F.: Microstructure, precipitation and mechanical properties of a titanium-tungsten alloyed hot rolled high strength steel. Materials Science and Engineering A 718, 2018, 56-63.

43. Webel J., Herges A., Britz D., Detemple E., Flaxa V., Mohrbacher H., Mücklich F.: Tracing microalloy precipitation in Nb-Ti HSLA steel during austenite conditioning. Metals 10(2), 2020, 243.

44. Zhao F., Hu H., Liu X., Zhang Z., Xie J.: Effect of billet microstructure and deformation on austenite grain growth in forging heating of a medium-carbon microalloyed steel. Journal Alloys and Compounds 869, 2021, 159326.

45. Zhao F., Jiang B., Xie J., Liu Y.: The optimized microstructure and properties of a V-Ti microalloyed forging steel by boron addition. Materials Letters 236(1), 2019, 440-443.

46. Zheng W., Yan X., Xion S., Wang G., Li G.: Pitting corrosion behavior of cerium treated HSLA steel induced by sulfide inclusions in $3.5 \mathrm{wt} \% \mathrm{NaCl}$ solution. Journal of Rare Earths 39(3), 2021, 348-356.

47. Zheng Y., Li X., Liu Y., Liu C., Dong L., Li H: Study of the kinetics of austenite grain growth by dynamic Ti-rich carbonitride dissolution in HSLA steel: in-situ obserwation and modeling. Materials Characterization 169, 2020, 110612.

48. ASTM E112-10, Standard test methods for determining average grain size. ASTM International, West Conshohocken, PA, 2010. 